Original article

Central Eur J Paed 2018;14(1):55-60

DOI $10.5457 /$ p2005-114.199

\title{
Age at surgery and outcomes of an undescended testis: A single center experience
}

\author{
Sanimir Suljendić, Edin Husarić, Almira Ćosićkić, Amir Halilbašić, Nešad Hotić, Emir Rahmanović
}

Clinic for Children's Diseases, University Clinical Centre Tuzla, Tuzla, Bosnia and Herzegovina

\author{
Correspondence: \\ sanimir1980@gmail.com \\ Tel.: + 38761738894 \\ Fax.: + 38735303702
}

Received: August 20, 2017

Accepted: November 16, 2017

Key words: Undescended Testis • Orchidopexy.

\begin{abstract}
Objective - To evaluate age at surgery and outcomes of undescended testis (UDT) of boys who underwent surgical treatment at our institution. Methods - The retrospective study was conducted from December 2006 until December 2016 analysing the medical documentation of boys with UDT who were treated with orchidopexy. Age of boys at the time of diagnosis, age at which orchidopexy was performed, results of intraoperative observations and treatment complications were analysed. Results - Orchidopexy was performed in 562 boys with UDT. The median age at the time of orchidopexy was 50.5 months (IQR 22 - 117); orchidopexy was most frequently performed between the ages of 4 and 6 in 35.2\% (198/562) boys, while the least number of boys $3.5 \%$ (20/562) underwent orchidopexy during the first year of life. The most common form was unilateral UDT with the prevalence of $93 \%$ (523/562), out of which $67.6 \%$ (380/562) of cases had UDT located in the inguinal canal. The rarest location of UDT was intraabdominal with the prevalence of 3.9\% (22/562). Complications such as retraction of testis out of scrotum, testicular atrophy, postoperative hernia and wound infection were observed in $1.7 \%$ (10/562), $0.53 \%$ (3/562), 1.2\% (7/562) and $0.88 \%$ (5/562), respectively. The efficacy of orchidopexy was $96.6 \%$. Conclusion - Although the most boys included in the study had surgery at a later age than recommended, the success rate of orhidopexy was significant with the small number of complications. Our findings support that orhidopexy is both the standard and the option for the successful management of UDT.
\end{abstract}

\section{Introduction}

Undescended testis (UDT) is a very common anomaly of the male genitalia affecting $2 \%-$ $4 \%$ of male infants and is more common in premature infants $(1,2)$. Since testicular descent occurs within $9-12$ months of life in significant number of children, the incidence of UDT decreases to $0.8 \%-1 \%$ at 1 year of age, after which the spontaneous descent of testes rarely occurs $(3,4,5)$. The mechanism of prenatal testicular descent is still partly obscure, however, it is known that dysgenesis of a testis itself, mechanical obstruction such as a narrow inguinal canal and a too short ductus deferens have a significant role, as well as endocrine (insufficient gonadotropin stimulation), genetic and environmental factors. Approximately $1 / 3$ of premature boys and up to $5 \%$ of full term boys have at least one UDT (7). The short term postnatal endogenous testosterone secretion reduces the incidence to $1 \%-2 \%$ after three months, while the incidence of UDT ranges from $0.3 \%$ to $0.4 \%$ at the age of 1 year. A strategy of watchful waiting is not indicated after six 
months of age since the spontaneous descent of testis rarely occurs after this period $(8,9)$. It is recommended that the UDT treatment should be started after 6 months of age and completed by the child's first birthday, because an early treatment minimises the potential risk of infertility as one of long term complications of UDT (10). On the other hand, the study results suggest that the treatment before the age 13 years does not lessen the risk of the malignant alteration $(10,11$, 12). There are two main types of UDT: retained and the ectopic testis (13). After UDT has been diagnosed it is necessary, without a delay, to initiate a hormone therapy, surgical treatment, or both $(6,14)$. Since UDT can result in impaired fertility, testicular malignancy, torsion and/or associated inguinal hernia, it is recommended to treat it by orchidopexy or surgical repositioning of the testis to the scrotum, which should be completed by the first year of life $(1,5,15)$.

The aim of this study was to evaluate age at surgery and outcomes of UDT in boys who underwent the surgical treatment at our institution.

\section{Methods}

The retrospective study was conducted analysing the medical documentation of boys with UDT who were treated at the Department of Paediatric Surgery of Clinic for Children's Diseases, University Clinical Centre Tuzla from December 2006 until December 2016. We analysed the following: age of boys at the time of diagnosis of undescended testis, age at which orchidopexy was performed, intraoperative observations and treatment complications. At our Clinic, the diagnosis and location of UDT is performed by physical scrotal examination while the boy is in standing, lying and sitting positions with the legs flexed at the hips and knees, and crossed feet; by manual assessment of the inguinal canal from the internal ring toward the scrotum trying to push subcutaneous structures toward the scrotum.

\section{Statistical analysis}

The data analysis was accomplished using the biomedical application software "MedCalc for Windows, version 15.11.4" (MedCalc Software, Ostend, Belgium). The variables with irregular distribution were presented as median and interquartile range (IQR). The obtained results were indicated by absolute and relative numbers. The age of boys at the time of diagnosis of undescended testis, age at which orchidopexy was performed, intraoperative observations and treatment complications were analysed.

\section{Results}

5314 children, 2840 boys and 2474 girls, were surgically treated at the Department of Paediatric Surgery of University Clinical Centre Tuzla from December 2006 until December 2016. Orchidopexy was performed in 562 or $19.8 \%$ boys with UDT. The median age of boys at the time of diagnosis of UDT was 20 months (IQR 3 - 48), while the median age at the time of orchidopexy was 50.5 months (IQR $22-117$ ). 93\% of boys were diagnosed with unilateral UDT. UDT was located in the inguinal canal in the majority of boys, 380 (67.6\%). The characteristics of the boys included in the study are shown in Table 1.

Orchidopexy was performed in $20(3.5 \%)$ boys with UDT by the first year of life. However, in the majority of boys 198/562 (35.2\%) orchidopexy was performed between the ages of 4 and 6 , while after the age 12 the surgical treatment of UDT was done in $86(15.3 \%)$ boys. $2 / 86(2.3 \%)$ boys aged 18 years underwent the surgical treatment of UDT (Table 2). 


\section{Table 1. Clinical characteristic of 562 boys with UDT}

\begin{tabular}{ll}
\hline Characteristic & $20(3-48)$ \\
\hline $\begin{array}{l}\text { Age at diagnosis of UDT } \\
\text { (months, median, IQR) }\end{array}$ & $50.5(22-117)$ \\
$\begin{array}{l}\text { Age at orchidopexy } \\
\text { (months, median, IQR) }\end{array}$ & $523(93)$ \\
$\begin{array}{l}\text { Unilateral UTD (n; \%) } \\
\text { Bilateral undescended testis (n; \%) }\end{array}$ & $39(6.9)$ \\
$\begin{array}{l}\text { Intra-abdominal position of UDT (n; \%) } \\
\text { UDT at the exit of the inguinal canal }\end{array}$ & $22(3.9)$ \\
(n; \%) & $160(28.5)$ \\
UDT in the inguinal canal (n; \%) & $380(67.6)$ \\
\hline
\end{tabular}

UDT $=$ Undescended testis: $\mathrm{IQR}=$ interquartile range.

\begin{tabular}{|c|c|}
\hline \multicolumn{2}{|c|}{$\begin{array}{l}\text { Table 2. Age at the surgical management of } \\
\text { undescended testes }\end{array}$} \\
\hline Age (yr) & n (\%) \\
\hline$\leq 1$ & $20(3.5)$ \\
\hline $2-3$ & $121(21.5)$ \\
\hline $4-6$ & $198(35.2)$ \\
\hline $7-12$ & $137(24.4)$ \\
\hline$\geq 12$ & $86(15.3)$ \\
\hline
\end{tabular}

Before the surgical treatment 2 boys received a hormone therapy, but without an anticipated outcome, while the hormone therapy was administered in 2 boys with intra-abdnominal position of both testes before the surgical treatment to achieve a response of testosterone secretion.

$10(1.7 \%)$ boys out of 526 who underwent orchidopexy experienced a complication: retraction of a testis out of the scrotum (in two boys with intra-abdominal position UDT, in five boys with UDT in the inguinal canal and in three boys with UDT at the exit of the inguinal canal). Postoperative hernia was found in seven $(1.2 \%)$ boys therefore they were reoperated after six months, and testicular atrophy occurred in three $(0.53 \%)$ boys (one had the intra-abdominal localization of UDT, two had UDT in the inguinal canal). Five boys $(0.88 \%)$ developed wound infection after surgery. The efficacy of the surgical treatment was $96.6 \%$.

\section{Discussion}

The retrospective ten years study was conducted with an aim of evaluating the boys' age at the time of orchidopexy and its outcomes. The majority of boys included in the study underwent surgical treatment of orchidopexy at the age of 4 to 6 years, while the least number of boys were operated by the first year of life. Our study results concur with the findings of other researchers who reported that the most common age at orchidopexy ranged between 45 and 62 months, and also the least number of boys included in those studies were surgically treated by the first year of life (16-23). Somewhat different results, however, were suggested by Hrivatakis et al. (24) who treated $24.4 \%$ of boys with orchidopexy before the second birthday, $57 \%$ of boys after the age of 2 years, and only $18.7 \%$ of boys underwent orchidopexy by the first year of life. On the other hand, Zöller et al. in their study (11) reported that orchidopexy was performed after the second year of life in $80 \%$ of boys, while Yiee et al. (25) performed orchidopexy by the age of 18 months in $87 \%$ of boys. Orchidopexy as the standard method of the treatment of UDT has its diagnostic as well as its therapeutic purpose. Similarly, for the intra-abdominal testes either orchidopexy or a laparoscopic approach can be used for exploration of UDT, i.e. the Fowler-Stephens manoeuvre (26). Often one technique may be replaced by the other one during the procedure if it is impossible to achieve the optimal outcome by the initially chosen technique. All boys included in this study underwent orchidopexy since the laparoscopy was not an available operative technique during the study period. Majority of boys in the study had the unilateral UDT. Similarly, in their study, Chan et al. (26) more frequently found the unilateral form in boys who underwent orchidopexy, while $2.9 \%$ of boys had the bilateral UDT. In this study, the majority of boys had the 
UDT in the inguinal canal, and the rarest location of UDT was intra-abdominal. Significantly different results were reported by other researchers. For example, in his study, Abolyosr (27) found that the UDT were high abdominal in $47.1 \%$ of boys, $31 \%$ of boys had the UDT in the inguinal canal, and $8 \%$ had the UDT at the exit of the inguinal canal. Similarly, Castillio et al. (28) found the intra-abdominal UDT in 55\% of boys. In this study, the efficacy of orchidopexy (the absence of complications such as recurrence, testicular atrophy, hernia, wound infection) in treatment of UDT was significantly high, and the results concur with the results of other researchers. Thus, Abaci et al. (29) reported on the efficacy of orchidopexy in $90 \%$ of cases, while Chan et al. (26) successfully performed orchidopexy in $90 \%$ of boys with the bilateral UDT, and Taran and Elder (30) suggested that orchidopexy was effective in $95 \%$ of boys with UDT found in the inguinal canal and in $90 \%$ of boys with UDT found intra-abdominally. In 64 studies which included 8425 boys with UDT, the efficacy of orchidopexy in testes located intraabdominally, in testes located in the inguinal canal, and in testes found at the exit of the inguinal canal was $74 \%, 87 \%$ and $92 \%$, respectively (31).

One of the possible complications after orchidopexy is testicular atrophy. Although a rare complication, the testicular atrophy occurs in $8 \%$ of cases if UDT is located distal to the inguinal canal, but also in 25\% if UDT is located intra-abdominally (32). Ciszek et al. (33) found the testicular atrophy in $9.8 \%$ of boys with the intra-abdominal position of NT, while Ashley et al. (1) reported on the atrophy after orchidopexy in 3\% of boys. Our results are somewhat different, only $0.57 \%$ of boys had the atrophy of testes. The similar results were reported by Chan et al. (26) who found that $0.29 \%$ of boys had the testicular atrophy after orchidopexy. The significantly low prevalence of orchidopexy complications (retraction of testes, postoperative hernia) was observed in boys included in our study, which concurs with the results reported by Ashley et al. (1). In their study, 2\% of boys had retraction of testes, $3 \%$ of boys had postoperative hernia.

\section{Limitation of study}

The major limitation of the study was the short time of observation. We presented the surgical outcomes of orchiopexy in boys during ten years, which is a short period of time, because successful orchiopexy should be defined as the functionally capable testis, not just the testis in the scrotum. This can be evaluated many years after surgical treatment, not just after an initial follow up.

\section{Conclusion}

The undescendend testis is the most common genital malformation in boys, and because of its long term complications it should be treated before the child's first birthday. Although the most boys included in the study had surgery at a later age than recommended, the success rate of orhidopexy was significant with the small number of complications. Our findings support that orhidopexy is both the standard and the option for the successful management of UDT.

Conflict of interest: The authors declare that they have no conflict of interest.

\section{References}

1. Ashley RA, Barthold JS, Kolon TF. Cryptorchidism: pathogenesis, diagnosis, treatment and prognosis. Urol Clin North Am. 2010;37:183-93.

2. Hutson JM, Balic A, Nation T, Southwell B. Cryptorchidism. Semin Pediatr Surg. 2010;19:215-24. 
3. Elder JS. The undescended testis. Hormonal and surgical management. Surg Clin North Am. 1988;68:983-1005.

4. Khatwa UA, Menon PS. Management of undescended testis. Indian J Pediatr. 2000;67:449-54.

5. Leissner J, Filipas D, Wolf HK, Fisch M. The undescended testis: considerations and impact on fertility. BJU Int. 1999;83:885-91.

6. Virtanen HE, Bjerknes R, Cortes D, Jorgensen N, Rajpert-De Meyts E, et al. Cryptorchidism: classification, prevalence and long-term consequences. Acta Paediatr. 2007;96:611-6.

7. Toppari J, Kaleva M. Maldescensus testis. Horm Res. 1999;51:261-9.

8. Docimo S, Silver RI, Crome W. The undescended testicle: diagnosis and treatment. Am Fam Physician. 2000;62(9):2037-48

9. Berkowitz GS, Lapinski RH, Dolgin SE, Gazella JG, Bodian CA, Holzman IR. Prevalence and natural history of cryptorchidism. Pediatrics. 1993;92:44-9.

10. Der Deutschen Gesellschaft für Kinderchirurgie, der Deutschen Gesellschaft für Urologie und der Deutschen Gesellschaft für Kinder und Jugendmedizin, vertreten durch die Arbeitsgemeinschaft für pädiatrische Endokrinologie (homepage on the Internet). Duesseldorf: AWMF Leitlinie nr 006/022, 2k, Hodenhochstand - Maldeszensus testis (update 2014 Jul 23; cited Aug 2009). Available from: http// www.awmf.org/leitlinien/detail/11/006-022.htlm.

11. Zöller G, Ringert, Hermann R. Hodenhochstand im Kindesalter - oft zu spät behandelt. Dtsch Arztebl. 2005;102:1750-2.

12. Pettersson A, Richiardi L, Nordenskjoid A, Kaijser M, Akre O. Age at surgery for undescended testis and risk of testicular cancer. N Engl JMed. 2007;356(18):1835-41.

13. Ramareddy RS, Alladi A, Siddappa OS. Ectopic testis in children: experience with seven cases. J Pediatr Surg. 2013;48(3):538-41.

14. Hadziselimovic F. Cryptorchidism, its impact on male fertility. Eur Urol. 2002;41:121-3.

15. Chung E, Brock GB. Cryptorchidism and its impact on male fertility: a state of art review of current literature. Can Urol Assoc J. 2011;5:210-4.

16. Bayne AP, Alonzo DG, Hsieh MH, Roth DR. Impact of anatomical and socioeconomic factors on timing of urological consultation for boys with cryptorchidism. J Urol. 2011;186:1601-5.

17. Chen YF, Huang WY, Huang KH, Hsieh JT, Lan CF, Chang HC. Factors related to the time to cryptorchidism surgery--a nationwide, population-based study in Taiwan. J Formos Med Assoc. 2014;113(12):915-20.

18. Jensen MS, Olsen LH, Thulstrup AM, Bonde JP, Olsen J, Henriksen TB. Age at cryptorchidism diagnosis and orchiopexy in Denmark: a population based study of 508,964 boys born from 1995 to 2009. J Urol. 2011;186:1595-1600.

19. Kokorowski PJ, Routh JC, Graham DA, Nelson CP. Variations in timing of surgery among boys who underwent orchidopexy for cryptorchidism. Pediatrics. 2010;126:576-82.

20. Moslemi MK. Evaluation of orchiopexy practice patterns in patients with cryptorchidism: A singlecentre study. J Pediatr Urol. 2014;10:230-2.

21. Springer A, Subramaniam R, Krall C, Fulop G. Orchidopexy patterns in Austria from 1993 to 2009. J Pediatr Urol. 2013;9:535-41.

22. Steckler RE, Zaontz MR, Skoog SJ, Rushton HG., Jr. Cryptorchidism pediatricians, and family practitioners: patterns of practice and referral. J Pediatr. 1995;127:948-51.

23. Upadhyay V, Kothari M, Manoharan M. The referral pattern for undescended testes in Auckland. N Z Med J. 2001;114:310-1.

24. Hrivatakis G, Astfalk W, Schmidt A, Hartwig A, Kugler T, Heim T, et al. The Timing of Surgery for Undescended Testis. Dtsch Arztebl Int. 2014;11(39): 649-57.

25. Yiee JH, Saigal CS, Lai J, Copp HL, Churchill BM, Litwin MS. Timing of orchiopexy in the United States: a quality-of-care indicator. Urology. 2012;80:1121-6.

26. Chan KWE, Lee KH, Wong HYV, Tsui SYB, Wong YS, Pang KY, et al. Use of laparoscopy as the initial surgical approach of impalpable testes: 10-year experience. World J Clin Pediatr. 2015;4(4):155-9.

27. Abolyosr A. Laparoscopic versus open orchiopexy in the management of abdominal testis: a descriptive study. Int J Urol. 2006;13(11):1421-4.

28. Castillo O J, Muñiz-Colon L, Escudero K, PerezBrayfield M. Laparoscopy in the surgical management of the non-palpable testis. Front Pediatr. 2014;2:28. 
29. Abacı A, Çatlı G, Anık A, Böber E. Epidemiology, Classification and Management of Undescended Testes: Does Medication Have Value in its Treatment? J Clin Res Pediatr Endocrinol. 2013;5(2):65-72.

30. Taran I, Elder JS. Results of orchiopexy for the undescended testis. World J Urol. 2006;24:231-9.

31. Docimo SG. The results of surgical therapy for cryptorchidism: a literature review and analysis. J Urol. 1995;154:1148-52.
32. Mathers MJ, Sperling H, Rübben H, Roth S, The Undescended Testis: Diagnosis, Treatment and Long-Term Consequences. Dtsch Arztebl Int. 2009;106(33):527-32.

33. Cisek LJ, Peters CA, Atala A, Bauer SB, Diamond $\mathrm{DA}$, Retik AB. Current findings in diagnostic laparoscopic evaluation of the nonpalpable testis. J Urol. 1998;160:1145-9. 